\title{
A TEMÁTICA MEDICAMENTOS COMO CONTEXTO NO ENSINO DE QUÍMICA EM UMA ESCOLA PÚBLICA DE UBÁ-MG
}

\author{
Tatiane da Rocha Carias ${ }^{1}$ \\ Taís Arthur Corrêa ${ }^{2}$ \\ Aline Aparecida Angelo ${ }^{3}$
}

\begin{abstract}
Resumo: A temática Medicamentos apresenta uma proposta interessante para o ensino de Química quando aplicados de forma contextualizada. O objetivo deste trabalho é a inserção do tema "medicamentos" como uma ferramenta para explicar funções orgânicas, relacionando o conteúdo de química com a automedicação, consumo excessivo e descarte de medicamento. Foram realizadas visitas à Escola Estadual Senador Levindo Coelho, situada na cidade de Ubá-MG, em que se coletaram dados através de questionários aplicados aos alunos e professores. A análise do livro didático possibilitou verificar a inserção do tema medicamentos no ensino de química. O conhecimento foi efetivado através de aulas expositivas e experimentais relacionando a temática proposta com o conteúdo de funções orgânicas. Durante o desenvolvimento deste trabalho pode-se perceber maior participação dos alunos quando contextualizado com assuntos de seu cotidiano.
\end{abstract}

Palavras-chave: Automedicação; Ensino de química; Contextualização.

\footnotetext{
${ }^{1}$ Química/UEMG - Ubá, Brasil. E-mail: tati_carias@hotmail.com.

2 Química/UEMG - Ubá, Brasil. E-mail: tais.correa@uemguba.edu.br.

${ }^{3}$ Química/UEMG - Ubá, Brasil. E-mail: alineapangelo@yahoo.com.br.
} 